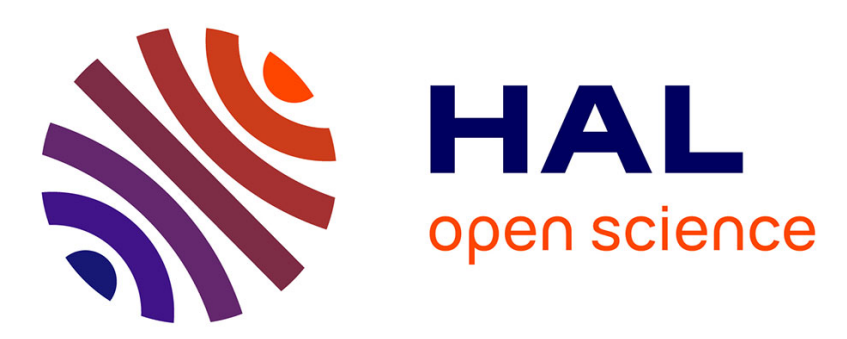

\title{
HRTEM Studies of Stress Assisted Sintered BaLa4Ti4O15
}

N.B. Selvaraj, M. Fernandes, Thibaud Denneulin, Etienne Snoeck, A.M.R. Senos, P.M. Vilarinho

\section{- To cite this version:}

N.B. Selvaraj, M. Fernandes, Thibaud Denneulin, Etienne Snoeck, A.M.R. Senos, et al.. HRTEM Studies of Stress Assisted Sintered BaLa4Ti4O15. Microscopy and Microanalysis, 2015, INCOMAM'14 International Conference on Microscopy and Microanalysis, 21 (Supp 5), pp.47-48. 10.1017/S143192761501404X . hal-01724221

\section{HAL Id: hal-01724221 \\ https://hal.science/hal-01724221}

Submitted on 12 Mar 2018

HAL is a multi-disciplinary open access archive for the deposit and dissemination of scientific research documents, whether they are published or not. The documents may come from teaching and research institutions in France or abroad, or from public or private research centers.
L'archive ouverte pluridisciplinaire HAL, est destinée au dépôt et à la diffusion de documents scientifiques de niveau recherche, publiés ou non, émanant des établissements d'enseignement et de recherche français ou étrangers, des laboratoires publics ou privés. 


\title{
HRTEM studies of stress assisted sintered $\mathrm{BaLa}_{4} \mathrm{Ti}_{4} \mathrm{O}_{15}$
}

\author{
Selvaraj, N. B ${ }^{1}$, Fernandes, $\mathrm{M}^{1}$, Denneulin, $\mathrm{T}^{2}$, Snoeck, ${ }^{2}$, Senos, A.M.R ${ }^{1}$ and Vilarinho, P.M ${ }^{1}$ \\ ${ }^{1}$ Department of Materials and Ceramics Engineering, CICECO, University of Aveiro, 3810-193 \\ Aveiro, Portugal. \\ ${ }^{2}$ CEMES-CNRS 29 rue Jeanne Marvig, BP 94347, 31055 Toulouse Cedex 4, France. \\ Email: nivasbabu@gmail.com
}

The role of interfaces on the grain growth of polycrystals during sintering has been recently recalled into attention and important theoretical work has been developed, supported by experimental results on ceramic oxide materials [1,2]. It was shown that by controlling the nature of the interfaces one can tune the grain growth during sintering and, therefore, the subsequent control of related properties is envisaged. One way to control the interface nature is by changing the sintering conditions and there are many studies proving the importance of the sintering temperature, holding time, heating rate and atmosphere, but very few about the effect of an external pressure applied during the consolidation process [3, 4].

In this work we are presenting a HRTEM study of $\mathrm{BaLa}_{4} \mathrm{Ti}_{4} \mathrm{O}_{15}$ (BLT) ceramics sintered under compressive stresses applied by Hot Pressing (HP) and Hot Isostatic Pressing (HIP) and the comparison with a free sintered sample. This study clearly reveals that the external pressure has a say on the nature of the grain boundaries in BLT.

BLT powders were prepared by conventional solid state route by calcining the stoichiometric proportion of the precursors at $1330^{\circ} \mathrm{C}$ for $3 \mathrm{~h}$. Free sintered samples were prepared by uniaxial pressing of BLT powders at $100 \mathrm{MPa}$, followed by sintering at $1530^{\circ} \mathrm{C}$ for $180 \mathrm{~min}$ in conventional (CS) way. Second set of samples were prepared by $\mathrm{HP}$ at $1250^{\circ} \mathrm{C}$, for $120 \mathrm{~min}$, with an external pressure of $65 \mathrm{MPa}$. Another set of samples were prepared by HIP at $1530^{\circ} \mathrm{C}$, for $90 \mathrm{~min}$, under a pressure of $60 \mathrm{MPa}$, the previously HP samples. Cross section and top view Scanning Electron Microscopy (SEM) photographs (XL 30 FEG, Philips Electronic Instruments, Mahwah, NJ and S4100, Hitachi, Tokyo, Japan) were acquired for microstructure evaluation. Both set of samples were thinned down to $20 \mu \mathrm{m}$ using precision ion polishing system (PIPS-Model 691; Gatan, Pleasanton, CA) for transmission electron microscopy (TEM) studies (SACTEM TECNAI-F20 and Hitachi HF3300 I2TEM).

SEM (Fig.1) revealed that the microstructure developments of CS samples are distinct from the stress assisted ones (HP and HP+HIP). In the stress assisted samples abnormal grain growth (AGG) was observed to have occurred during sintering, together with textured effects. Grain elongation was found to be enhanced in those samples, as well, by the effect of the external pressure applied during sintering. No second phases were observed in all the samples. HRTEM images (Fig. 2, 3) show clean grain boundaries for CS samples, while the stress assisted samples show crystal imperfections ie, line defects and surface defects in an unusual amount when compared to CS. Stacking faults were observed in both HP and HP+ HIP samples indicating that changes in distance between the atomic layers occurred due to the external pressure applied during sintering. The density of defects in the crystal structure was analyzed using geometrical phase analysis (GPA), which confirmed that CS samples are almost free of imperfections, while stress assisted samples are showing a quite large strain distribution.

This research is sponsored by the Reference Framework (QREN/I\&DT/11428/2009) of the European Regional Development Fund (ERDF). NBS is supported by the FCT grant SFRH/BPD/82158/2011. The authors acknowledge the European Union funding, seventh 
framework program under a contract for an integrated infrastructure initiative 312483ESTEEM2.

\section{References :}

[1] Dillon, S.J., et al., Acta Materialia, 2007. 55(18): p. 6208-6218.

[2] Se-Min An., et al., Acta Materialia 60 (2012) 4531-4539.

[3] S-J L. Kang, Sintering Densification, Grain Growth, and Microstructure, Elseviers 2004. [4] J. Besson and M. Abouaf, Mater Sci Eng A, 10937 (1989).
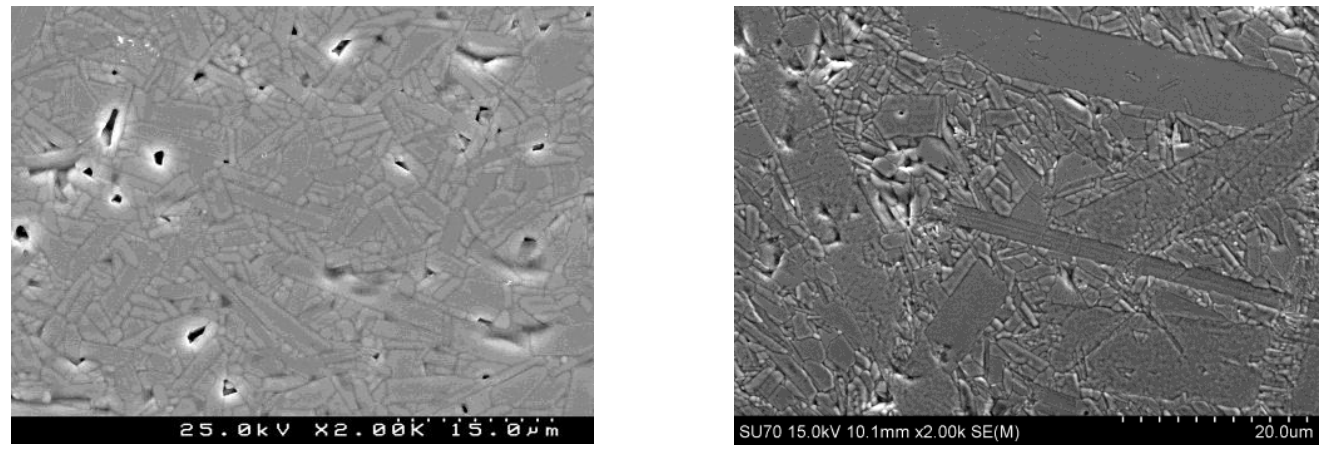

Figure 1. SEM image of CS (left) and HP+HIP sample (right).
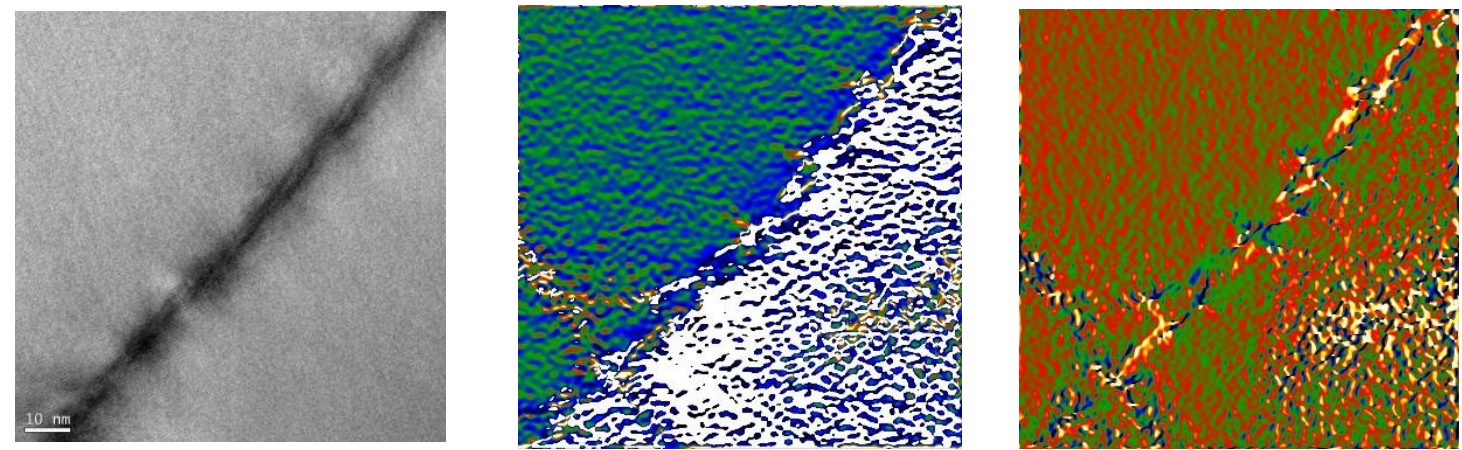

Figure 2. HRTEM image of CS sample (left), showing minimal fringe rotation (middle) and deformation (right).
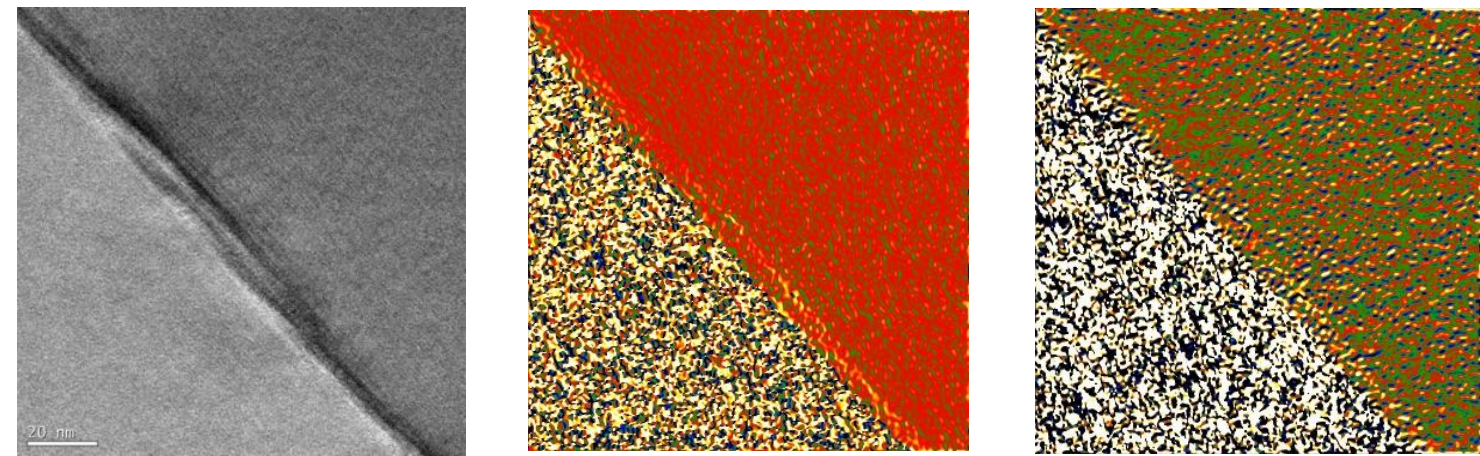

Figure 3. HRTEM image of HP sample (left), showing observable amount of fringe rotation (middle) and deformation (right). 